\title{
Yürüme analizi ve temel kavramlar
}

\author{
Gait analysis and basic concepts
}

\author{
Güneş Yavuzer
}

Haliç Üniversitesi Sağlık Bilimleri Yüksekokulu Fizyoterapi ve Rehabilitasyon Bölümü, İstanbul

\begin{abstract}
İnsanoğlunun iki ayak üzerinde yürümek üzere evrimleşmesi üç milyon yılda başarılan bir süreçtir. Ritmik olarak uygulanan hareketlerin koordinasyonu supraspinal mekanizmaların kontrolü altında spinal kordda lokomotor jeneratorlar tarafından oluşturulur. Bu ritmik hareketin analiz edilmesi M.Ö. 320 yıllarına kadar gitmektedir. Ancak anladığımız anlamda üç boyutlu olarak yürüme analizini klinik kullanıma sokan araştırmacılar Verne Inman ve Jacquelin Perry olmuştur. Bu gelişme ile birlikte kantitatif yürüme analizi ile yürüyüş bozuklukları objektif ve güvenilir bir şekilde tanımlanmış ve tedavi kararları alınabilmiştir. Ancak, elde edilen kinetik, kinematik ve dinamik EMG verileri ancak deneyimli klinisyenler tarafından yorumlandığında klinik düzeyde yarar sağlayabileceği unutulmamalıdır.
\end{abstract}

Anahtar sözcülk: yürüme analizi
Evolution of human to walk on two feet is a process accomplished in three million years. The coordination of rhythmic movements is produced by locomotor generators at spinal cord level under the control of supraspinal mechanisms. The analysis of these rhythmic movements goes beyond 320 BC. However, it was Verne Inman and Jacqueline Perry who have presented the three dimensional gait analysis into clinical use as the way we understand. Along with this progress, by using quantitative gait analysis, gait disorders were defined objectively and reliably as well as treatment decisions were made. But it should be kept in mind that the kinetic, kinematic, and dynamic EMG data obtained can be relevant clinically only if they are interpreted by experienced clinicians.

Key word: gait analysis
Y ürüme bir yerden bir yere gidebilmek amacıyla tekrarlanan ritmik hareketler zinciridir. Dört ayak üzerinde son derece dengeli ve rahat olan yürüyüş, iki ayak üzerinde zorlaşır ve kusursuz bir nöronal kontrol gerektirir. Kazanılması 3 milyon yıl süren iki ayak üzerinde dik yürüme becerisi içgüdüler ve öğrenme ile şekillenir. İçgüdülere dayanan temel yürüyüş paterni üzerine öğrenilen davranışların eklenmesi ile ırklara, kişiye hatta kişinin o andaki ruh haline özgü yürüyüş paternleri yerleşir. ${ }^{[1-11]}$

Yürüme için gereken hareketler zinciri supraspinal mekanizmaların kontrolü altında spinal kordda lokomotor jeneratorlar tarafindan oluşturulur. Bir kişinin istenen yönde ve hızda ilerlemesi ve dış sarsıntılar ile başedebilmesi için supraspinal kontrol gereklidir. Supraspinal kontrol olmadan sadece spinal kord düzeyinde dengeyi korumak amaçlı basit tepkisel cevaplar ve primitif adımlama oluşturulabilir. ${ }^{[12,13]}$ Uzun süre yorulmadan yürüyebilmek için beyin, omurilik, periferik sinirler, kaslar, kemik ve eklemler birlikte çalışmalı, eklem hareketleri ve kas kasılmalarının zamanı ve gücü yeterli olmalıdır. Motor yetiler yanı sıra vücut segmentlerinin uzaydaki konumu ve hızı hakkında sağlıklı ve zamanında duysal geri bildirim de normal yürüme için gereklidir. Vücut segmentlerinin hareketleri ve kas kasılmalarının zamanlamaları yürüme için gereken metabolik enerji ihtiyacını en düşük düzeyde tutacak şekilde ayarlanmıştır. Bu hassas uyumu aksatan her türlü yapı ve fonksiyon bozukluğu metabolik ihtiyacı arttırır, yürüyüş verimini düşürür.

Yürüme analizi, nöromusküloskeletal sistem fonksiyonlarının değerlendirilmesi ve sonuçların sayılar ve grafikler ile yorumlanmasıdır. İnsan gözü, yürüme sırasında milisaniyeler içinde oluşan hareketleri

- İletişim adresi: Prof. Dr. Güneş Yavuzer, Haliç Üniversitesi Sağlık Bilimleri Yüksekokulu Fizyoterapi ve Rehabilitasyon Bölümü, Şişli, İstanbul Tel: 0212 - 9242444 e-posta: gunesyavuzer@hotmail.com

- Geliș tarihi: 23 Temmuz 2014 Kabul tarihi: 23 Temmuz 2014 
algılamakta yetersiz kaldığı için ayrıntılı ve güvenilir inceleme yöntemlerine ihtiyaç duyulmuştur. Bu yöntemler ile gözle anlaşılamayacak kurvet, moment ve kas aktivitelerini değerlendirmek de mümkündür. Doğru tanı ve başarılı bir tedavi için normal yürüme bilinmeli, patolojik olandan ayırt edilmeli, yürümeyi bozan ana neden ve bu nedeni telafi etmek için yapılan hareketler anlaşılmalıdır. Bunun için, yürümenin tüm bileşenlerini eksiksiz kaydedecek, sayısal veriye dönüştürecek, karşılaştırma ve tekrar incelemeye imkan verecek, tedavi sonrası veya zaman içinde oluşan değişiklikleri değerlendirmeye olanak sağlayacak sistemler gereklidir.

İnsan hareketinin analizi M.Ö. 350 yılında Aristo ile başlamaktadır. Aristo eklem hareketlerini kas kasılmasının yaptırdığını, Galen ise kas kasılmasını sinirlerin yönettiğini bulmuştur. Rönesans döneminde Galileo'nun öğrencisi Borelli, 19. yüzyılda ise Marey insan yürüyüşü ile ilgili dinamik çalışmalar yapmışlardır. 1830'larda Weber kardeşlerin öncülüğünde yapılmış modern anlamda yürüyüş analizi çalışmaları bulunmaktadır. Fotoğraf makinelerinin saniyenin onda birinde görüntü kaydedebilecek kadar geliştirilmesi ile, yürüyen veya hareket eden hayvan ve insan fotoğraflarının çekilmesi ve değerlendirilmesi çağı başlamıştır. ${ }^{[1]}$ Edward Muybridge 1872 yılında Kaliforniya Valisi Leland Stanford tarafından tırıs giden bir atın dört ayağının da yerden kesilip kesilmediği iddiasını karara bağlamak üzere fotoğraf çekmeye çağrılmıştır. Döneminin en başarılı fotoğrafçılarından olan Muybridge bir dizi özel kamera aracılığıla çektiği fotoğraflarla atın dört ayağının da aynı anda havada olduğu bir anı belgelemeyi başarmıştır. Muybridge daha sonra Pennsylvania Üniversitesi'nde hareket analizi araştırmalarını sürdürmüş, 1877 yılında saniyenin 2000'de birinde resim çekebilen özel kameralar kullanarak hayvanlar ve insanın çeşitli hareketleri üzerine geniş çalışmalar yapmış, çok ayrıntılı kitaplar yazmıştır. ${ }^{[1]}$ Yürüme analizinin gelişmesinde bir sonraki aşama 1895'te Braune ve Fisher'in fotoğraf görüntülerini sayısal değişkenlere dönüştürmesidir. Araştırmacılar bu amaçla on bir küçük ampulü ekstremitelere yerleştirmiş, denek hareket ederken seri fotoğraflar çekmiş ve bu fotoğraflar üzerinde her ampulün yer değişimini tek tek ölçerek hareketin grafiklerini kaydetmeyi başarmışlardır. 1930'larda Eberhart ve Inman fotoğraf makinasının objektifi önünde dönen delikli bir disk kullanarak bu deneyleri daha ayrıntılı olarak tekrar etmişlerdir. Tüm bu çalışmalar 20. yüzyılda biyomekanik biliminin gelişmesinde öncülük etmiştir. Ancak her saniyede 20-30 kare film çekerek, bunlar üzerinde belirli noktaların yer değişimini tek tek elle ölçme yöntemi ile yapılan yürüme analizi çok yavaş ve zahmetli olduğu için yaygınlaşamamış, yalnızca az sayıdaki araştırma merkezinde kullanılabilen çok kısıtlı bir yöntem olarak kalmıştır. 1950'lerde başlayan çalışmalarıla bugün bildiğimiz anlamda bilimsel yürüme analizini klinik kullanıma sokan araştırmacılar Verne Inman ve Jacquelin Perry'dir. ${ }^{[1,2]}$ Bilgisayar teknolojisinin gelişmesi ile klinik kullanıma yönelik yürüme analizi sistemleri geliştirilmiş ve dünyanın birçok ülkesinde kullanıma girmiştir. Laboratuvarda kullanılan yürüme analizi teknikleri, bugün giderek yerini hareketin doğal ortamda analizine bırakmaktadır.

Birçok yürüme patolojisi deneyimli hekimlerin yaptığı gözlemsel analiz ile anlaşılabilse de sorunu sayısal olarak ortaya koymak, kaydedip daha sonra yeniden değerlendirmek ve uygulanan tedavilerin etkinliğini araştırmak için kantitatif yürüme analizi teknolojisi kullanılmaktadır. Kantitatif yürüme analizinde önce hastanın öyküsü alınır, fizik muayenesi ve kas iskelet sistemi muayenesi yapılır. Bu aşamada eklem hareket açıklıkları, kas gücü, selektif kas kontrolü ve kas tonusu değerlendirilir. Hekim hastanın tanısı ve kendi değerlendirmesi sonucunda yürüme analizi için kullanılan yöntemlerden hastanın gereksinimleri için gerekli olanları uygular. Kantitatif analiz için hastanın boyu, kilosu, diz ve ayak bileği eklem genişliği ve bacak uzunlukları ölçülerek kaydedilir. Yerleri modelleme çalışmalarında belirlenmiş olan anatomik noktalara işaret cihazları yerleştirilir, değerlendirilmesi istenen kaslara elektromiyografi (EMG) elektrodları konulur. Uygulanan işaret cihazları optik kameralardan gönderilen infraruj ışığını yansıtırlar. Yansıyan ışığı algılayan kameralar aracılığıyla hareket veriler bilgisayara aktarılır, ayrıca yere monte edilen kuvvet platformları ile ölçülen yer tepkimesi kuvvetleri de bilgisayara iletilir. Bu verilere dinamik EMG ve enerji ölçümleri de eklenebilir.

Denekler genelde çıplak ayak, gerekiyorsa ayakkabı, ortez veya yürümeye yardımcı cihazlar ile yürütülebilirler. Veri toplama fazı hastanın motor ve bilişsel yetilerine göre 30-60 dakika sürebilir. Toplanan verilerin bilgisayarda işlenmesi ve rapor aşaması, değerlendiren hekimin deneyimine ve hastanın sorunlarına bağlı olarak 1-3 saat sürer. Toplanan tüm bilgiler özel yazılımlar aracılığıyla sayısal verilere dönüştürülür. Son olarak veriler hastanın klinik durumu ile birlikte değerlendirilerek hekim tarafindan yorumlanır ve rapor yazılır. Yürüyüş analizinde klinisyenlere yardımcı olabilecek yüzlerce veri çıkarılabilir. Ancak bu verilerin çokluğu ve değişen koşullarda (örneğin, yürüme hızı) gösterdikleri farklılıklar bazen olayı tümüyle içinden çıkılmaz bir hale de sokabilir. Bu nedenle yürüyüş analizi istenen hastanın beklenen patolojisine göre bir hedef belirlenmeli ve o hedefe yönelik daha önceden üzerinde fikir birliğine varılmış, güvenilirliği gösterilmiş sonuç parametreleri kullanılmalıdır. 
Kantitatif yürüme analizi ile yürüyüş bozuklukları objektif ve güvenilir bir şekilde tanımlanır. Veriler arşivlenebilir, tekrar değerlendirilebilir, karşılaştırılabilir. Bu verilerden alınan geri bildirimler ile eğitim verilebilir, uygulanacak tedavi belirlenebilir ve yeni tedavi protokolleri geliş̧tirilebilir; tedavi etkinliği değerlendirilebilir, bilimsel araştırma yapılabilir. Yürüme analizi birçok kas iskelet sistemi sorununda, ${ }^{[14-25]}$ serebral palsi, ${ }^{[26]}$ inme, ${ }^{[27-29]}$ parkinson, ${ }^{[30]}$ omurilik hasar. ${ }^{[31]}$ gibi nörolojik hastalıklarda, ampütelerde, ${ }^{[32]}$ spor yaralanmalarında, ${ }^{[33]}$ spastisite tedavisinde, ${ }^{[34]}$ ameliyat ve diğer tedavi girişimlerinin planlanmasında, ${ }^{[35]}$ ortez ve protez uygulamalarında tedavi sonuçlarının değerlendirilmesinde ${ }^{[36,37]}$ ve tıp dışında sinema endüstrisinde de kullanılmaktadır.

\section{GÖZLEMSEL ANALiZ}

Yürüyüşün gözlenmesi rutin kas iskelet sistemi muayene yöntemlerinden birisidir. Yürüyüş belli bir sıra dahilinde, önce önden sonra her iki yandan gözlenmelidir. Yürüme alanının uzunluğu 8-10 m, genişliği ise en az $3 \mathrm{~m}$ olmalıdır. Gözlemsel yürüme analizinde, yürüme bozukluğunun birincil nedenlerini kompansatuvar hareketlerden ayırabilmek ve bozukluğun nedenini belirlemek zordur. Örneğin inme sonrası hemiparetik kişilerde basma fazında diz hiperekstansiyonu çok belirgin olabilir. Bu tablonun sadece gözlemsel analiz ile nedeni (kuadriseps veya kalça fleksörlerinde kas güçsüzlügü, ayak bileği plantar fleksiyon kontraktürü veya gastrosoleusta spastisite) anlaşılamaz. Dolayısıyla yürümeyi bozan nedenin tanısını koyabilmek için daha gelişmiş tekniklere başvurmak gerekebilir. Gözleme dayalı analizin yetersiz kaldığı diğer noktalar, kayıt tutulamaması ve çok sayıda vücut kısmını birlikte hareket ederken incelemenin güçlüğüdür. Bu nedenle video çekimlerinden yararlanılabilir. Hasta yürürken önden (frontal düzlem) ve yandan (sagittal düzlem) kısa süreli çekimler yapılır. Kameranın hastanın pelvisi yükssekliğinde üç ayaklı sehpaya yerleştirilmesi, ışıklandırmanın yeterli olması, standart bir sıra ile çekimlerin tekrarlanması, çekim tarihlerinin titizlikle not alınması çalışmanın verimini arttıracaktır. Video görüntüleri hastanın tekrarlanan değerlendirmelerinde, deneyimlerin paylaşımı, asistan ve öğrenci eğitimi amaçlarıyla kullanılır. ${ }^{[1]}$

\section{KINEMATIK ANALIZ}

Kinematik analiz ile vücudun uzaydaki hareketi incelenir. Gövdenin, pelvisin, bacakların ve ayakların her üç plandaki eklem açıları, lineer ve açısal hız ve ivmeleri ölçülür ve sayısal veri olarak kaydedilir. Hareketin üç boyutlu olarak değerlendirilmesi ve kaydedilebilmesi için en az beş kamera kullanımı önerilmektedir. Yazılım programları, hasta üzerindeki işaret cihazlarından yansıyan sinyallerin uzaydaki yer değişimi ile eklem açısındaki değişikliği hesaplar. Yürüme sırasında, bir zaman biriminden diğer zaman birimine olan yer değişiminden hız, hız değişiminden ise ivme hesaplanabilir. Kinematik veriler, optik kameralar, ultrasonik kayıt ediciler, ayak şalterleri, üzerinde alıcılar bulunan yürüme yolları ve elektrogonyometreler kullanılarak kayıt edilebilir.

\section{KINETIK ANALIZ}

Kinetik analizde yer tepkimesi kuvvetleri, eklem momentleri ve eklem güçleri gibi hareketi oluşturan kuvvetler incelenir. Kuvvet platformları ile direkt ölçülebilen tek veri yer tepkimesi kurveti vektörüdür (YTKV). Analiz öncesi toplanan antropometrik ölçümler, kinematik veriler ve YTKV verileri kullanılarak "invers dinamik" yöntemi ile kalça, diz ve ayak bileği eklemindeki moment ve güçler hesaplanır. YTKV ölçümü için deneğin kuvvet platformuna tek ayağı ile ve tek bir kez basması istenir. Kuvvet platformu yer düzlemi ile aynı seviyede olmalı ve üzerinden geçerken hasta platformu fark etmemeli, adımlarını ayarlamamalıdır. Hasta platformun nerede olduğunu bilirse o zaman üzerine basmaya çabalayacağından normal yürüme biçimi bozulur. Hasta kuvvet platformuna basarak geçtiğinde basan ayağın oluşturduğu YTKV bilgisayar tarafindan kaydedilir. YTKV diyagramında sagittal düzlemde çift tepe paterni gözlenir. Birinci tepe basma fazı ortasında yere aktarılan kuvveti, ikinci tepe ise salınım öncesinde yerin itme kuvvetini gösterir. Kuvvet platformları kinematik sistemlerle birlikte kullanıldığında ayak bileği, diz ve kalça eklemine etki eden momentler ve eklemlerde oluşan güçler hesaplanabilir. YTKV ölçüldükten sonra eklemlerde oluşan kuvvetleri hesaplamak için "link segment modeli” ile "invers dinamik analiz yöntemi" kullanılır. İnvers dinamik uygulaması için kuvvet platformundan elde edilen YTKV, alt ekstremitenin tüm segmentlerinin kinematik verileri ve antropometrik veriler bilgisayar ortamında bir araya getirilir. Kalça, diz ve ayak bileğine etki eden kuvvetler ve güçler hesaplanır. Bir eklemde hareketi oluşturmak için birçok kas kasıldığından, hesaplanan moment kasılan agonist ve antagonist kasların aktivitelerinin toplam değerini (net momenti) gösterir. Ayak bileği, kalça ve diz eklemleri için sagittal, frontal ve transvers düzlemlerde ayrı ayrı momentler hesaplanır. Güç (power) bir eklem etrafında kasılan kasların enerjiyi üretme veya absorbe etme hızı olarak tanımlanır; eklem açısal hızının eklemdeki momentle çarpımından oluşur. Kaslar eksentrik olarak kasıldıklarında güç absorbe ederler ve güç grafiği negatiftir. Konsantrik olarak kasıldıklarında ise güç üretirler ve güç grafiği pozitiftir. İzometrik kasılma esnasında eklemde hareket olmadığından güç üretilmez veya absorbe edilmez. 


\section{DINAMIK ELEKTROMIYOGRAFi}

Dinamik EMG yürüyüşte oluşan kas aktivitesinin elektrodlar yardımıyla kaydedilmesidir. Dinamik EMG, incelenen kasların kasılma zamanlamasını ve süresini gösterir. Elektrodlarla kaydedilen EMG sinyalleri, kablolar ya da radyo dalga telemetri sistemi ile bir bilgisayara aktarıır, artefaktları giderici ve sinyali netleştirici filtreleme işlemlerinden sonra kayıt edilir. Yürüme analizinde EMG kaydının önemi, kas aktivitesinin yürüme siklusunun hangi fazında oluştuğunu göstermesidir. Dinamik EMG, kas aktivitesinin ne zaman oluştuğuna dair objektif bilgi vermekle birlikte, kinematik analiz olmadan patolojik aktiviteyi kompansatuvar aktiviteden ayırt edemez. Kinetik verilerde oluşturulan veya emilen gücün hangi kas grubu ile gerçekleştirildiğine karar vermede dinamik EMG verileri kullanılır.

\section{ENERJi TÜKETIMININ HESAPLANMASI}

Normal yürüme enerji tüketimi açısından çok hesapIı olsa da, hızlanma amacıyla beş birim, frenleme ve şok absorpsiyonu için ise sekiz birim enerji harcanır. Normal yürüme siklusu bozulup gövde ve bacaklarda çeşitli kompansatuvar hareketler ortaya çıktığında enerji tüketimi artar. Enerji tüketimi solunum havasından $\mathrm{O}_{2}$ tüketimi esas alınarak hesaplanır. $\mathrm{O}_{2}$ tüketiminin tayini hastanın ne kadar rahat yürüyebildiğini en güvenilir şekilde gösteren ölçüm yöntemidir. ${ }^{[1]}$ Yürüme analizi esnasında enerji tüketimi hesaplanırken tercih edilen yöntem $\mathrm{O}_{2}$ tüketimi ile $\mathrm{CO}_{2}$ üretiminin her soluk havasında ardışık olarak ölçülmesidir. Bu işlem, çıplak ayakla yürüyen olguda 6 dakika süreyle yapılır. Gerekiyorsa koltuk değneği, baston veya yürüteç kullanılabilir. Yürünen mesafe dakikalık aralıklarla ölçülür. Hastanın dakikadaki $\mathrm{O}_{2}$ tüketimi plato çizdiğinde 3 dakika süreyle hesaplama yapılır. Yürüme güçlüğü olan bir insanın $\mathrm{O}_{2}$ maliyeti aynı yolu yürüyen sağlıklı insana göre daha yüksektir. Ölçümleri yorumlarken, $\mathrm{O}_{2}$ tüketiminin hıza bağlı olarak arttığını, yaşa bağlı değişiklikler ve cihazlarla veri toplamada güvenilirlik sorunları olduğunu hatırda tutmak gerekir. ${ }^{[1]}$

\section{YÜRÜME ANALIZI LABORATUVARLARININ YETERSIZLIKLERI}

Kantitatif yürüme analizi, gelişmiş ve pahalı teknoloji, geniş alan, iyi eğitim ve tecrübe, özveri ve ekip çalışması gerektirir. Gelişmiş bilgisayar teknolojisine rağmen klinik ve araştırma amaçlı uygulamalar çok zaman almaktadır. Tüm ölçüm yöntemlerinde olduğu gibi yürüme analizi laboratuvarlarında da ölçümlerin ve verilerin güvenilirliğini bozan hatalar olur. Olası hata nedenleri, değerlendirilen hastadan, cihazdan veya değerlendiriciden kaynaklanabilir. Tetkik, laboratuvar ortamında ve şort ile yapıldığı ve kişiye birçok kablo ve alıcı yerleştirildiği için kişi günlük yaşamından farklı bir şekilde yürüyebilir. Kullanılan sistemin günlük kalibrasyonlarının yapılmaması, kayıt sırasında elektrod ve işaret cihazlarının yanlış yerleştirilmesi, verileri yorumlayan ekibin dikkatsizliği veya tecrübesizliği de sonuçların yanlış değerlendirilmesine neden olabilir. Kantitatif yürüme analizi yöntemlerinin değişik patolojilerin değerlendirilmesinde güvenilirliği gösterilmiştir ve bu konudaki çalışmalar sürmektedir. ${ }^{[38,39]}$ Kantitatif yürüme analizi verilerini doğru ve etkili olarak kullanabilmek için klinisyenin belli konularda yeterli bilgi ve deneyime sahip olması gerekmektedir. Elde edilen kinetik, kinematik ve dinamik EMG verileri ancak deneyimli bir klinisyen tarafından yorumlandığında klinik düzeyde yarar sağlayabilmektedir. Bu amaçla, normal yürümenin biyomekaniği, kas-iskelet sisteminin anatomi ve fizyolojisi, patolojik yürümenin özellikleri ve analiz sürecine ait potansiyel zayıflıkların iyi düzeyde bilinmesine ihtiyaç vardır.

\section{KAYNAKLAR}

1. Yalçın S, Özaras N. Yürüme Analizi. İstanbul: Avrupa Matbaacılık; 2001.

2. Perry J. Gait Analysis: Normal and Pathological Function. Thorofare, NJ: SLACK Incorporated; 1992.

3. Hening EM, Meyer EANH. Physical Medicine and Rehabilitation (Gait Analysis, State of the Art Reviews, Volume 16/Number 2). Esquenazi A, editor. Hanley \& Belfus, Inc. 2002.

4. Adams JM, PerryJ. Gait Analysis: Clinical Application. In: Rose J, Gamble JG, editors. Human Walking, 2nd ed. Baltimore: William \& Wilkins; 1994. p.139-64.

5. Craik RL, Oatis CA, editors. Gait Analysis: Theory and Application. St Louis: Mosby-Year Book, Inc.; 1995.

6. Gage J. Gait Analysis in Cerebral Palsy. London: Mac Keith Press; 1991.

7. Güler HC. Yürüyüş analizi: Temel kavramlar ve uygulama. In: Beyazova M, Kutsal YG, editörler: Fiziksel Tıp ve Rehabilitasyon, 2. baskı. Güneş Tıp Kitabevi; 2011. p.401-26.

8. Kerrigan DC. Introduction/Prologue. In: DeLisa JA, editor. Monograph 002: Gait Analysis in the Science ofRehabilitation. Washington, DC: Veterans Health Administration; 1998.

9. Winter DA. The Biomechanics \& Motor Control of Human Gait: normal, elderly, and pathological, 2nd ed. Waterloo, Ontario: University of Waterloo Press; 1991.

10. Whittle MW. Gait Analysis: an Introduction, 4th ed. Philadelphia: Butterworth Heineman. Elsevier; 2007.

11. Kirtley C. The Temporal-Spatial Parameters in Clinical Gait Analysis: Theory and Practice. Philadelphia: Churchill Livingstone-Elsevier; 2006.

12. Burke RE, Degtyarenko AM, Simon ES. Patterns of locomotor drive to motoneurons and last-order interneurons: clues to the structure of the CPG. J Neurophysiol 2001;86(1):447-62.

13. Burke RE. The central pattern generator for locomotion in mammals. Adv Neurol 2001;87:11-24.

14. Cayir A, Yavuzer G, Sayli RT, Gurcay E, Culha V, Bozkurt M. Evaluation of joint findings with gait analysis in children with hemophilia. J Back Musculoskelet Rehabil 2014;27(3):30713. CrossRef 
15. Akşahin E, Yüksel HY, Yavuzer G, Muratlı HH, Celebi L, Biçimlioğlu A. Quantitative gait characteristics of children who had successful unilateral clubfoot operation. Acta Orthop Traumatol Turc 2010;44(5):378-84. CrossRef

16. Oken F, Yildirim O, Oken O, Gulcek M, Yavuzer G, Ucaner A. Short or long fusion after thoracolumbar burst fractures does not alter selected gait parameters: a preliminary study. J Orthop Res 2011;29(6):915-8. CrossRef

17. Marangoz S, Atilla B, Gök H, Yavuzer G, Ergin S, Tokgözoğlu AM, Alpaslan M. Gait analysis in adults with severe hip dysplasia before and after total hip arthroplasty. Hip Int 2010;20(4):466-72.

18. Oken OF, Yildirim AO, Yavuzer G, Gülcek M, Unal VS, Uçaner A, Oken O. Gait symmetry in patients with unilateral partial hip arthroplasty. Eklem Hastalik Cerrahisi 2010;21(2):86-90.

19. Kulcu DG, Yavuzer G, Sarmer S, Ergin S. Immediate effects of silicone insoles on gait pattern in patients with flexible flatfoot. Foot Ankle Int 2007;28(10):1053-6.

20. Omeroğlu H, Yavuzer $G$, Biçimoğlu A, Ağuş $H$, Tümer $Y$. No detectable major changes in gait analysis after soft tissue release in DDH. Clin Orthop Relat Res 2008;466(4):856-61. CrossRef

21. Yavuzer G, Sonel B, Süldür N, Ergin S. Effects of intra-articular hylan G-F 20 injections on clinical and biomechanical characteristics of the knee in osteoarthritis. Int J Rehabil Res 2005;28(4):371-4.

22. Yavuzer G, Ergin S. Effect of cane usage on clinical and gait characteristics of patients with ostearthritis of knee. Romatizma 2002; 17:150-5.

23. Gök H, Ergin S, Yavuzer G. Kinetic and kinematic characteristics of gait in patients with medial knee arthrosis. Acta Orthop Scand 2002;73(6):647-52.

24. Öztürk E, Ataman Ş, Yavuzer G. Gait characteristics of patients with ankylosing spondylitis. In: 5th Mediterranean Congress of Physical and Rehabilitation Medicine Antalya; September 30-October 04, Antalya, Türkiye; 2004. p.121.

25. Yavuzer G, Yetkin I, Toruner FB, Koca N, Bolukbasi N. Gait deviations of patients with diabetes mellitus: looking beyond peripheral neuropathy. Eura Medicophys 2006;42(2):127-33.

26. Yavuzer G, Sonel B, Kutlay Ş, Ergin S. Use of gait analysis in clinical decision-making process of patients with spastic cerebral palsy. Journal of Physical Medicine and Rehabilitation 2005;51:1-5.

27. Yavuzer G. Walking after stroke: Interventions to restore normal gait pattern after stroke. (Doktora tezi), Hollanda, Erasmus Üniversitesi, 2006
28. Yavuzer G, EserF, Karakus D, Karaoglan B, Stam HJ. The effects of balance training on gait late after stroke: a randomized controlled trial. Clin Rehabil 2006 Nov; 20(11):960-9.

29. Yavuzer G, Geler-Külcü D, Sonel-Tur B, Kutlay S, Ergin S, Stam HJ. Neuromuscular electric stimulation effect on lowerextremity motor recovery and gait kinematics of patients with stroke: a randomized controlled trial. Arch Phys Med Rehabil 2006;87(4):536-40.

30. Gök H, Kutlay Ş, Gürsel YK, Sonel B, Turan EB, Usar S, Akbostancı MC. Parkinson hastalığında kinematik yürüme analizi ve klinik testler ile ilişkisi. Parkinson Hastalığı ve Hareket Bozuklukları Dergisi 2004;7(1):7-12.

31. Ulkar B, Yavuzer G, Guner R, Ergin S. Energy expenditure of the paraplegic gait: comparison between different walking aids and normal subjects. Int J Rehabil Res 2003;26(3):213-7.

32. Segal AD, Orendurff MS, Klute GK, McDowell ML, Pecoraro JA, Shofer J, Czerniecki JM. Kinematic and kinetic comparisons of transfemoral amputee gait using C-Leg and Mauch SNS prosthetic knees. J Rehabil Res Dev 2006;43(7):857-70.

33. Yavuzer G, Ulkar B, Binnet M, Ergin S. Gait deviations in patients with anterior cruciate ligament deficiency. In: 2nd World Congress of the International Society of Physical Medicine and Rehabilitation Medicine; Prague, Czech Rebuplic; 2003. p.101.

34. Esquenazi A, Mayer N, Garreta R. Influence of botulinum toxin type A treatment of elbow flexor spasticity on hemiparetic gait. Am J Phys Med Rehabil 2008;87(4):305-10.

35. Kay RM, Dennis S, Rethlefsen S, Reynolds RA, Skaggs DL, Tolo $V T$. The effect of preoperative gait analysis on orthopaedic decision making. Clin Orthop Relat Res 2000;(372):217-22.

36. Gök $H$, Küçükdeveci $A$, Altinkaynak $H$, Yavuzer $G$, Ergin $\mathrm{S}$. Effects of ankle-foot orthoses on hemiparetic gait. Clin Rehabil 2003;17(2):137-9.

37. Yavuzer G, Ergin S. Effect of an arm sling on gait pattern in patients with hemiplegia. Arch Phys Med Rehabil 2002;83(7):960-3.

38. Yavuzer G, Oken O, Elhan A, Stam HJ. Repeatability of lower limb three-dimensional kinematics in patients with stroke. Gait Posture 2008;27(1):31-5.

39. Gök H, Ergin S, Yavuzer G. Reliability of gait measurements in normal subjects. The Journal of Rheumatology and Medical Rehabilitation 2002;13(2):76-80. 